\title{
Einige neue Sphingiden (Lep.).
}

Von A. Cloß (Berlin-Friedenau).

\section{Platysphinx phyllis R. et J. $\hat{o}$.}

Vor einigen Jahren erhielt ich von Le Moult in Paris eine Kollektion von Schwärmern aus Franz.-Kongo (Fort Crampel), unter denen sich auserlesene Seltenheiten befanden, wie z. B. die von mir in der Gub. Ent. Zschr. (28. Februar 1914) beschriebene Nephete triangulifera. Eine zur Gattung Platysphinx R. et J. gehörige Spezies scheint das bisher unbekannte ô zu P. phyllis R. et J. zu sein. Es stimmt genau mit der bei Rothschild-Jordan (Rev. Sphing., I, p. 226) gegebenen Beschreibung, sowie der ebenda (Pl. I) befindlichen Abbildung der Type des $q$ überein, bis auf den beim ô naturgemäß schlankeren Habitus und das nicht verdunkelte Saumfeld der Vorderflügel.

\section{Xylophanes hamemanni spec. nov.}

Der Schwärmer hat zunächst Ähnlichkeit mit Xylophanes porcus Hb., unterscheidet sich jedoch von diesem bei näherer Betrachtung in wesentlichen Punkten.

Vor allem erscheinen die Vorderflügel durch den stark vorgezogenen Hinterwinkel breiter, der Innenrand ist dadurch sehr stark ausgebuchtet, der Außenrand fast gerade, die Flügelspitze sichelförmig vorspringend. Die Farbe ist rötlich olivenbraun, der Außensaum der Tegulae nicht weiß, sondern rotbräunlich, er setzt sich über das Auge bis zum Palpus fort, die Fühler sind ebenfalls rotbräunlich. Die Vorderflügel sind fast zeichnungslos, ein kleines schwarzes Stigma und eine schwache schwärzliche submarginale Punktreihe, sowie ein bei $R_{3}$ vorspringendes, schwach grau bestäubtes Saumfeld sind die einzigen Unterbrechungen der rötlich olivenbraunen Grundfarbe. Die Hinterflügel sind dunkelbraun, vom Analwinkel her mit dem Ansatz einer rötlichen Binde, die bei $\mathbf{M}^{\prime}$ aufhört. Die Fransen der Hinterflügel schmal weiß. Die Unterseite des Körpers und der Flügel rötlichgrau, das Wurzelfeld der Vorderflügel bis über den Discus hinaus schwärzlichgrau, der Vorderrand von der Grundfarbe, der Innenrand gelblichweiß, von dem Saum beider Flügel verläuft eine sehr stark ausgeprägte (am stärksten am Vorderrand der Vorderflügel) schwarze Fleckenreihe.

\section{Type: 1 ô, Mexiko.}

Ich benenne diese neue Spezies zu Ehren des langjährigen verdienten Vorstandsmitgliedes des Berlirer Entomologenbundes, Herrn E. Hannemann: Xylophanes hannemanni. 
3. Celerio euphorbiae L. subsp. euphorbiae sinensis subsp. nov.

Soviel bisher bekannt wår, erstreckt sich das Verbreitungsgebiet des Wolfsmilchschwärmers und seiner Unterarten vom Westen des europäischen Festlandes östlich bis Nordchina (Shantung) (subsp. e. costata Nordm.) und südlich bis zư den Kanarischen Inseln (subsp. e. tithymali Boisd.) und Nordwestindien (subsp. e. nervosa R. et J.). Ich erhielt vor einiger Zeit ein Paar aus dem südlichen China (Kanton), das zu keiner der nördlich und westlich davon vorkommenden Subspezies paßt und daher als Vertreter einer eigenen Unterart anzusehen sein dürfte. Die in Betracht kommenden Subspezies sind: C. e. costata Nordm. (Costalrand des Vorderflügels breit olivenbraun, das helle Mittelfeld zu einem schmalen Streifen reduz ert, das dunkle Diskalband von hellen Adern durchquert (von Shantung) und $C$. e. nervosa $\mathrm{R}$. et J. (ähnlich wie der vorige). Mit keiner von beiden haben die Stücke aus Kanton die geringste Ähnlichkeit, der Vorderrand der Vorderflügel ist schmal olivenfarbig, das Mittelfeld rötlich ledergelb, von der Wurzel aus, die olivenbraun, am Innenrand schwarz mit weißen Haaren ist, dunkel gesprenkelt. Die beiden Costalflecke sind sehr ausgeprägt, der proximale groß und oval, der distale scharf dreieckig. Die olivenfarbene Keilbinde ist sehr scharf und distal scharf schwarz begrenzt, das Saumfeld rotgrau. Die Schulterdecken haben keinen weißen Oberrand, der Hinterleib zeigt die bekannte Färbung des Typus. Die Unterseite ist matt rosenrot, die Vorderflügel mit schwärzlichem, bis über den Discus hinausgehendem Basalfleck, an seinem Ende steht ein länglicher schwarzer Fleck, das Saumfeld ist gezackt, rötlichgrau. $\hat{o}$ und $q$ stimmen in Färbung und Zeichnung vollständig überein. Type: $\hat{o}$ o aus Kanton (Südchina).

Sämtliche vorbeschriebenen Stücke befinden sich in meiner Sammlung.

\section{Ueber einige von Herrn E. Hintz gesammelte äthiopische Hymenoptera und Lepidoptera.}

\section{Von Embrik Strand (Berlin).}

Schon wiederholt habe ich Gelegenheit gehabt, über von Herrn Ingenieur E. Hintz gesammelte afrikanische Arthropoden zu berichten ${ }^{1}$ ). Auch durch das im folgenden behandelte, jetzt dem.

$\left.{ }^{1}\right)$ Strand, Über die von Herrn Ingenieur E. Hintz in Kamerun gesammelten Hymenoptera mit Beiträgen zur Kenntnis afrikanischer 


\section{$2 \mathrm{BHL}$ Biodiversity Heritage Library}

1917. "Einige neue Sphingiden." Entomologische Mitteilungen 6, 33-34. https://doi.org/10.5962/bhl.part.10102.

View This Item Online: https://www.biodiversitylibrary.org/item/38722

DOI: https://doi.org/10.5962/bhl.part.10102

Permalink: https://www.biodiversitylibrary.org/partpdf/10102

\section{Holding Institution}

Smithsonian Libraries

\section{Sponsored by}

Smithsonian

\section{Copyright \& Reuse}

Copyright Status: NOT_IN_COPYRIGHT

This document was created from content at the Biodiversity Heritage Library, the world's largest open access digital library for biodiversity literature and archives. Visit BHL at https://www.biodiversitylibrary.org. 